\title{
Article \\ Synthesis and Properties of Nitrogen-Doped Carbon Quantum Dots Using Lactic Acid as Carbon Source
}

\author{
Kaixin Chang ${ }^{1}$, Qianjin Zhu ${ }^{1}$, Liyan $\mathrm{Qi}^{1}{ }^{1}$, Mingwei Guo ${ }^{1}$, Woming Gao ${ }^{1}$ and Qinwei Gao ${ }^{1,2, *(1)}$ \\ 1 College of Chemical Engineering, Nanjing Forestry University, Nanjing 210037, China; \\ ckx851127@gmail.com (K.C.); 18260077835@163.com (Q.Z.); 18362985223@163.com (L.Q.); \\ guomw199876@163.com (M.G.); orangtreechina@gmail.com (W.G.) \\ 2 Jiangsu Co-Innovation Center of Efficient Processing and Utilization of Forest Resources, Nanjing Forestry \\ University, Nanjing 210037, China \\ * Correspondence: gqw@njfu.com.cn
}

check for updates

Citation: Chang, K.; Zhu, Q.; Qi, L.; Guo, M.; Gao, W.; Gao, Q. Synthesis and Properties of Nitrogen-Doped Carbon Quantum Dots Using Lactic Acid as Carbon Source. Materials 2022, 15, 466. https://doi.org/ $10.3390 / \mathrm{ma} 15020466$

Academic Editor: Antonio Polimen

Received: 13 December 2021

Accepted: 6 January 2022

Published: 8 January 2022

Publisher's Note: MDPI stays neutral with regard to jurisdictional claims in published maps and institutional affiliations.

Copyright: (C) 2022 by the authors. Licensee MDPI, Basel, Switzerland. This article is an open access article distributed under the terms and conditions of the Creative Commons Attribution (CC BY) license (https:// creativecommons.org/licenses/by/ $4.0 /)$.

\begin{abstract}
Nitrogen-doped carbon quantum dots (N-CQDs) were synthesized in a one-step hydrothermal technique utilizing L-lactic acid as that of the source of carbon and ethylenediamine as that of the source of nitrogen, and were characterized using dynamic light scattering, $X$-ray photoelectron spectroscopy ultraviolet-visible spectrum, Fourier-transformed infrared spectrum, high-resolution transmission electron microscopy, and fluorescence spectrum. The generated N-CQDs have a spherical structure and overall diameters ranging from 1-4 nm, and their surface comprises specific functional groups such as amino, carboxyl, and hydroxyl, resulting in greater water solubility and fluorescence. The quantum yield of N-CQDs (being 46\%) is significantly higher than that of the CQDs synthesized from other biomass in literatures. Its fluorescence intensity is dependent on the excitation wavelength, and N-CQDs release blue light at $365 \mathrm{~nm}$ under ultraviolet light. The $\mathrm{pH}$ values may impact the protonation of N-CQDs surface functional groups and lead to significant fluorescence quenching of N-CQDs. Therefore, the fluorescence intensity of N-CQDs is the highest at $\mathrm{pH}$ 7.0, but it decreases with $\mathrm{pH}$ as $\mathrm{pH}$ values being either more than or less than $\mathrm{pH}$ 7.0. The N-CQDs exhibit high sensitivity to $\mathrm{Fe}^{3+}$ ions, for $\mathrm{Fe}^{3+}$ ions would decrease the fluorescence intensity of N-CQDs by $99.6 \%$, and the influence of $\mathrm{Fe}^{3+}$ ions on $\mathrm{N}-\mathrm{CQD}$ s fluorescence quenching is slightly affected by other metal ions. Moreover, the fluorescence quenching efficiency of $\mathrm{Fe}^{3+}$ ions displays an obvious linear relationship to $\mathrm{Fe}^{3+}$ concentrations in a wide range of concentrations (up to $200 \mu \mathrm{M}$ ) and with a detection limit of $1.89 \mu \mathrm{M}$. Therefore, the generated N-CQDs may be utilized as a robust fluorescence sensor for detecting $\mathrm{pH}$ and $\mathrm{Fe}^{3+}$ ions.
\end{abstract}

Keywords: nitrogen-doped carbon quantum dots; fluorescence; $\mathrm{pH}$ value; $\mathrm{Fe}^{3+}$ ion; lactic acid

\section{Introduction}

Carbon quantum dots (CQDs) are regarded as a novel class of fluorescence nanomaterials. Meanwhile CQDs exhibit many unique advantages, compared with traditional fluorescent nanomaterials, such as excellent biocompatibility [1], good solubility [2], low toxicity [3,4], remarkable photostability [5], as well as their small size. Hence CQDs are considered as one of the most attractive alternative to traditional fluorescent materials, and have been used in drug delivery carriers [6,7], biological imaging [8,9], fluorescent probes $[10,11]$, photovoltaic devices [12,13], and so on.

CQDs were originally founded by Xu et al. [14] in 2004, who utilized an electrophoretic separation and purification technique for the purification of single-walled carbon nanotubes generated from arc-discharge soot, and named as carbon quantum dots by Su et al. [15] in 2006. Over the past decade, many synthetic methods of CQDs have been reported, such as arc-discharge [14], laser ablation [16], electrochemical oxidation [17], microwave method [18], and hydrothermal treatment [19]. These synthetic methods have two main purposes: one purpose is to crack different carbon source materials, and the other is the 
carbonization of small molecules or polymers [20]. Meanwhile, a variety of carbon-sources materials, including graphite [21], citric acid [22,23], watermelon peel [24], saccharum officinarum juice [25], scindapsus leaves [26], and others, have been developed for the preparation of CQDs. Therefore, various synthesis methods and carbon sources may obtain CQDs with various sizes, structures and excitation wavelengths, which will have an obvious impact on the fluorescence emission intensity of CQDs. The two disadvantages including low yield of CQDs and a small amount of functional groups on CQD surface limit the fluorescence performance and application of CQDs [27]. When CQDs are doped by nitrogen, sulfur, and other elements, their spectral properties and applications may be improved. Thus N-doped carbon quantum dots (N-CQDs) and S-doped carbon dots (S-CQDs) can be obtained, while the doping of $\mathrm{N}$ and $\mathrm{S}$ elements may change the electron density, structure, and composition of the doped CQDs, leading to the increase of fluorescence intensity of N-CQDs and S-CQDs [28,29], which will boost CQDs performance and broaden CQDs application. Recently, much research has reported on the N-doped and N/other atom co-doped CQDs. The N-doped CQDs are widely used in the field of probes, especially for metal ions detection by probes. Either in nature or in animals, iron is an important element, especially $\mathrm{Fe}^{3+}$ ions. Therefore, it is essential to detect $\mathrm{Fe}^{3+}$ ions. Qi et al. [30] utilized a one-step hydrothermal approach to manufacture nitrogen-doped carbon quantum dots $\mathrm{N}-\mathrm{CQDS}$ with rice residue as carbon source and glycine as nitrogen source, respectively, and then used N-CQDs as the probe to detect $\mathrm{Fe}^{3+}$ ions and tetracycline antibiotics. Du et al. [31] adopted hydrothermal technique using ascorbic acid and thioglycolic acid to synthesize sulfur-doped CQDs, which were used as the fluorescent probe to detect $\mathrm{Fe}^{2+}$ and $\mathrm{Fe}^{3+}$ ions in oral ferrous gluconate samples. Chen et al. [32] synthesized N-CQDs by hydrothermal method with p-phenylenediamine and ammonia, and the N-CQDs were considered as a multi-functional fluorescence sensor for detecting $\mathrm{pH}$ and $\mathrm{Fe}^{3+}$ ions.

L-lactic acid is a widely used bio-based chemical containing hydroxyl and carboxyl groups, while ethylenediamine contains amino groups, which may be good candidates for preparing N-CQDs. In this work, we used a one-step hydrothermal technique to create $\mathrm{N}-\mathrm{CQD}$ utilizing L-lactic acid as carbon source and ethylenediamine as nitrogen source, respectively. The obtained N-CQDs featuring surface functional groups present excellent water solubility and fluorescence. The N-CQDs were investigated in terms of their morphology, surface structure, and optical properties. Those N-CQDs have been synthesized that were spherical particles with overall diameters ranging from 1-4 nm. When irradiated by ultraviolet light with the wavelength of $365 \mathrm{~nm}, \mathrm{~N}-\mathrm{CQDs}$ would emit blue light, and their emission wavelength reaches to the maximum of $414 \mathrm{~nm}$ during the excitation wavelength of ultraviolet light being $310 \mathrm{~nm}$, which indicates that the optical characteristics of N-CQDs depend on the excitation wavelength. Meanwhile, the fluorescence of N-CQDs also reveals a pH-dependent dependency. Furthermore, the obtained N-CQDs showed better specificity and sensitivity to $\mathrm{Fe}^{3+}$ ions, suggesting that they might be exploited as fluorescent probe of $\mathrm{Fe}^{3+}$ ions. The research of N-CQDs prepared from lactic acid would expand the scope of application of lactic acid.

\section{Materials and Methods}

\subsection{Materials}

L-lactic acid (A.R., 90\%) was purchased from Musashino Chemical (Yichun, China) Corporation. Ethylenediamine (A.R.), hydrochloric acid (A.R.), $\mathrm{NaOH}$ (A.R.), $\mathrm{FeCl}_{3}$ (A.R.), $\mathrm{FeCl}_{2} \cdot 4 \mathrm{H}_{2} \mathrm{O}$ (A.R.), $\mathrm{CuCl}_{2} \cdot 2 \mathrm{H}_{2} \mathrm{O}$ (A.R.), $\mathrm{MgCl}_{2} \cdot 6 \mathrm{H}_{2} \mathrm{O}$ (A.R.), $\mathrm{NiCl}_{2} \cdot 6 \mathrm{H}_{2} \mathrm{O}$ (A.R.), $\mathrm{CaCl}_{2}$ (A.R.), $\mathrm{SnCl}_{2}$ (A.R.), $\mathrm{KCl}$ (A.R.), $\mathrm{CoCl}_{2} \cdot 6 \mathrm{H}_{2} \mathrm{O}$ (A.R.), and $\mathrm{LiCl} \cdot 2 \mathrm{H}_{2} \mathrm{O}$ (A.R.) were all bought from Nanjing Chemical Reagent Company (Nanjing, China). A dialysis bag with a molecular weight cut-off of 1000 Da was purchased from Shanghai Yuanye Bio-Technology Co., Ltd. (Shanghai, China). The deionized water was purified using an Ulupure system (Nanjing Youpu Environmental Protection Equipment Co., Ltd, Nanjing, China) throughout all the experiments. All reagents used were available commercially and did not involve purification. 


\subsection{Synthesis of Nitrogen-Doped Carbon Quantum Dots}

We synthesized N-CQDs through one-step hydrothermal method employing L-lactic acid as carbon source and ethylenediamine as nitrogen source [26,33] (Scheme 1). $30.0 \mathrm{~g}$ L-lactic acid and $2 \mathrm{~mL}$ ethylenediamine were mixed with $30 \mathrm{~mL}$ deionized water in a $100 \mathrm{~mL}$ three-necked flask, then the solution was heated up to $150{ }^{\circ} \mathrm{C}$ and reacted for $12 \mathrm{~h}$. The reaction solution was then allowed to cool naturally before even being centrifuged for $10 \mathrm{~min}$ at 10,000 rpm, The supernatant was collected and transferred to a dialysis bag with a molecular weight cut-off of $1000 \mathrm{Da}$, then dialyzed for $72 \mathrm{~h}$ with deionized water in the glass flume. In the end, the dialyzed supernatant was freeze-dried in vacuum freeze dryer to yield solid N-CQDs.

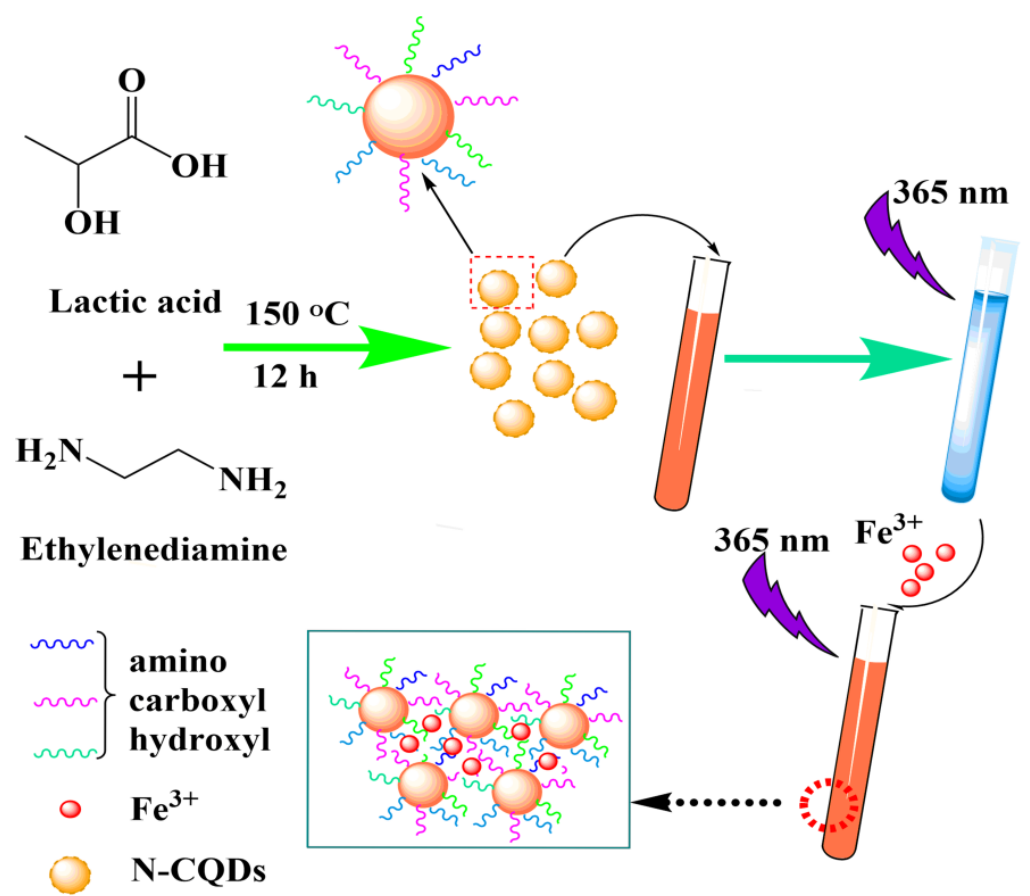

Scheme 1. Schematic illustration of one-step manufacturing for N-CQDs and the detection of $\mathrm{Fe}^{3+}$ using N-CQDs.

In this section, the LG16-A high-speed centrifuge (Lab Centrifuge, Beijing, China) was used to centrifuge the sample to eliminate big particles of contaminants, while the FD-1A-50 freeze drier (Boyikang Experimental Instrument Co., Ltd., Beijing, China) was used for freeze drying to create N-CQDs solids.

\subsection{Characterization Methods}

The UV-vis spectrophotometer UV-2450 (Shimadzu, Kyoto Japan) was applied to detect UV-vis spectra. $0.05 \mathrm{mg} / \mathrm{mL} \mathrm{N}$-CQDs aqueous solution prepared by dispersing the solid NCQDs in deionized water was used for both UV-vis and fluorescence spectra below. Fouriertransformed infrared spectroscopy (FTIR) was measured with the FTIR-360 (PerkinElmer, Waltham, MA, USA). The scanning range for the FTIR spectra was $450-4500 \mathrm{~cm}^{-1}$, and the $\mathrm{KBr}$ tablet was being used as a carrier. The microstructures of $\mathrm{N}$-CQDs were examined using JEM-2100 (JEOL, Tokyo, Japan) High-resolution transmission electron microscopy (HRTEM). To determine the elemental composition, X-ray photoelectron spectroscopy (XPS) using an $\mathrm{Al} \mathrm{K} \alpha$ monochromatized source was studied on AXIS UltraDLD (Kratos, Kyoto, United Kingdom). Fluorescence spectra were recorded on Perkinelmer Fluorescent FL6500 (PerkinElmer, Waltham, Massachusetts, USA). All fluorescence spectra were measured with the excitation slit being $5 \mathrm{~nm}$, the emission slit being $10 \mathrm{~nm}$, and the scanning speed being 
$1200 \mathrm{~nm} / \mathrm{min}$. Zetasizer Nano-ZS (Malvern instruments, Malvern, UK) was being used to evaluate the size and distribution of N-CQDs nanoparticles.

\subsection{Quantum Yield of Nitrogen-Doped Carbon Quantum Dots}

Quinine sulfate dissolved in $0.1 \mathrm{M}$ sulfuric acid is used as the standard sample, and its quantum yield $\left(Q_{S}\right)$ is 0.54 . The quantum yield of N-CQDs $\left(Q_{N}\right)$ is calculated that used the following equation [34,35].

$$
Q_{N}=Q_{S} \frac{I_{N}}{I_{S}} \frac{A_{S}}{A_{N}} \frac{\varphi_{N}^{2}}{\varphi_{S}^{2}}
$$

where $Q$ stands for the quantum yield and I for the integrated area of fluorescence intensity, while $A$ for the absorbance and $\varphi$ for the refractive index of the solvent (being 1.33). The standard sample and N-CQDs are denoted by the subscripts $S$ and $N$, respectively.

\subsection{Effect of $\mathrm{pH}$ Value on the Fluorescence Intensity of $\mathrm{N}$-CQDs}

A certain amount of N-CQDs solid was dissolved in deionized water to yield $0.05 \mathrm{mg} / \mathrm{mL}$ $\mathrm{N}-\mathrm{CQD}$ s solution. Aqueous solutions with $\mathrm{pH}$ values being from 1 to 14 were prepared with hydrochloric acid and sodium hydroxide, respectively. $1 \mathrm{~mL}$ of $\mathrm{N}-\mathrm{CQDs}$ solution and $1 \mathrm{~mL}$ hydrochloric solution (or $\mathrm{NaOH}$ solution) with different $\mathrm{pH}$ values were added to a quartz cuvette and mixed for $1 \mathrm{~min}$, and then the fluorescence test was performed at ambient temperature. All fluorescence spectra were recorded at $310 \mathrm{~nm}$ for excitation, and $414 \mathrm{~nm}$ for emission.

\subsection{Fluorescence Detection of $\mathrm{Fe}^{3+}$ Ions}

The above-mentioned aqueous solution of N-CQDs had a concentration of $0.05 \mathrm{mg} / \mathrm{mL}$. The chlorides containing various metal ions (including $\mathrm{Li}^{+}, \mathrm{Ca}^{2+}, \mathrm{Co}^{2+}, \mathrm{Cu}^{2+}, \mathrm{Fe}^{3+}, \mathrm{Mg}^{2+}$, $\mathrm{Fe}^{2+}, \mathrm{Ni}^{2+}, \mathrm{Sn}^{2+}$ and $\mathrm{K}^{+}$) were, respectively, dissolved in deionized water to prepare various chloride solutions with the concentration of $1 \mathrm{mM}$. To investigate the selectivity of N-CQDs aqueous solution to various metal ions, $0.5 \mathrm{~mL}$ chloride solution containing different metal ions and N-CQDs aqueous solution with a volume of $2 \mathrm{~mL}$ were added to a quartz cuvette and mixed at ambient temperature for $1 \mathrm{~min}$ before even being detected. To evaluate the detection range of $\mathrm{Fe}^{3+}$ ions and the sensitivity of $\mathrm{N}-\mathrm{CQDs}$ to $\mathrm{Fe}^{3+}$ ions, $0.5 \mathrm{~mL}$ of $\mathrm{Fe}^{3+}$ solutions with their concentrations varying from $0 \mu \mathrm{M}$ to $200 \mu \mathrm{M}$ were mixed with N-CQDs aqueous solution with a volume of $2 \mathrm{~mL}$ at ambient temperature for $2 \mathrm{~min}$, and then the mixed solutions were detected. $0.5 \mathrm{~mL} \mathrm{FeCl}_{3}$ solution and $0.5 \mathrm{~mL}$ other chloride solution were mixed with $\mathrm{N}-\mathrm{CQDs}$ aqueous solution with a volume of $2 \mathrm{~mL}$, and then the mixture solutions were detected to determine the fluorescence quenching of N-CQDs triggered by $\mathrm{Fe}^{3+}$ together with other metal ions.

\section{Results}

\subsection{The Morphology and Surface Composition of N-CQDs}

The N-CQDs were characterized using HRTEM to determine their morphology and surface functional groups. The HRTEM images of N-CQDs (Figure 1a) display that N-CQDs are spherical in morphology with diameters ranging from 1-4 nm (Figure 1b), which is consistent with prior literatures [36]. 

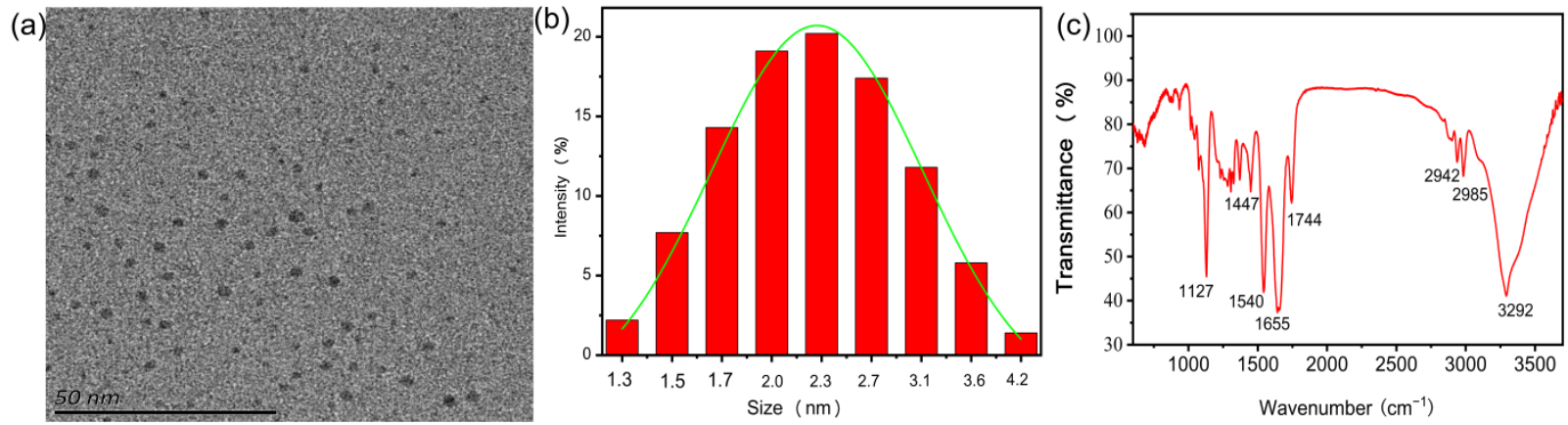

Figure 1. (a) HRTEM images of N-CQDs, (b) Histogram of N-CQDs size distribution, (c) FTIR spectrum of N-CQDs.

An FTIR test was conducted to analyze the functional groups on the surface of NCQDs. The FTIR spectrum of N-CQDs in Figure 1c demonstrates a peak at $1447 \mathrm{~cm}^{-1}$ corresponding to the stretching vibration band of the amine $\mathrm{C}-\mathrm{N}$ bond [37], and the peak at $3292 \mathrm{~cm}^{-1}$ owing to the stretching vibration bands of $\mathrm{O}-\mathrm{H}$ and $\mathrm{N}-\mathrm{H}$ [38], indicating the existence of amino functional groups. Meanwhile, the stretching vibration of $\mathrm{C}=\mathrm{C}$ is associated with the peak at $1540 \mathrm{~cm}^{-1}[39,40]$. Stretching $\mathrm{C}-\mathrm{H}$ of alkyl groups results in the two peaks at 2942 and $2985 \mathrm{~cm}^{-1}[35,41]$. The peak at $1744 \mathrm{~cm}^{-1}$ owing to carboxyl $\mathrm{C}=\mathrm{O}$ bonds indicates carbonyl groups in N-CQDs [42], whereas the peak at $1655 \mathrm{~cm}^{-1}$ due to amide $\mathrm{C}=\mathrm{O}$ indicates the amide groups of $\mathrm{N}-\mathrm{CQDs}$ [37]. the stretching vibration of $\mathrm{C}-\mathrm{O}$ of carbonyl groups causes the peak at $1127 \mathrm{~cm}^{-1}$ [43]. The FTIR results clearly illustrate that nitrogen was effectively doped into the CQDs and are consistent with those of XPS below.

The surface chemical composition and element status of N-CQDs were investigated further utilizing X-ray photoelectron spectroscopy (XPS). The XPS spectrum of N-CQD in Figure 2a shows three peaks at $532.3 \mathrm{eV}, 286 \mathrm{eV}$ and $400.4 \mathrm{eV}$, corresponding to O1s, $\mathrm{C} 1 \mathrm{~s}$ and N1s, respectively $[26,44,45]$, indicating that N-CQDs are mostly constituted of carbon, nitrogen, and oxygen. The high resolution XPS spectrum of $\mathrm{C} 1 \mathrm{~s}$ in Figure $2 \mathrm{~b}$ shows five peaks at $284.6 \mathrm{eV}, 285.5 \mathrm{eV}, 286.4 \mathrm{eV}, 287.1 \mathrm{eV}$ and $288.3 \mathrm{eV}$ that may be traced to $\mathrm{C}=\mathrm{C}, \mathrm{C}-\mathrm{C}, \mathrm{C}-\mathrm{N}, \mathrm{C}-\mathrm{O}$ and $\mathrm{C}=\mathrm{O}$ bonding on the surface of $\mathrm{N}-\mathrm{CQDs}[26,46]$. In Figure 2c, the high resolution XPS spectrum of N1s displays two peaks at $401.3 \mathrm{eV}$ and $399.8 \mathrm{eV}$ caused by $\mathrm{C}-\mathrm{N}$ and $\mathrm{N}-\mathrm{H}$, respectively $[32,47]$. The high resolution XPS spectrum of O1s in Figure $2 \mathrm{~d}$ exhibits two peaks at $531.5 \mathrm{eV}$ and $532.4 \mathrm{eV}$, which may be traced to $\mathrm{C}-\mathrm{O}$ and $\mathrm{C}=\mathrm{O}$, respectively $[48,49]$. The results of XPS, together with those of HRTEM and FTIR show that N-CQDs were effectively fabricated. Moreover, N-CQDs samples possess carboxyl, hydroxyl and amino groups, resulting in N-CQDs' excellent water solubility.

\subsection{Optical Performance of $N-C Q D s$}

The UV-Vis absorption spectrum was used to characterize the optical property of the generated N-CQDs. The UV-Vis absorption spectrum of N-CQDs aqueous solution in Figure 3a exhibits two absorbance bands severally centered at $220 \mathrm{~nm}$ and $320 \mathrm{~nm}$. The peak at $220 \mathrm{~nm}$ is ascribable to the $\pi-\pi^{*}$ transition for $C=C$ bond [32], while the peak at $320 \mathrm{~nm}$ is owing to the $\mathrm{n}-\pi^{*}$ transition of $\mathrm{C}=\mathrm{O}$ bond or surface defects of N-CQDs [36]. As seen in the inset in Figure 3b, the aqueous solution of N-CQDs was yellow in visible light and emitted blue fluorescence with the wavelength of $365 \mathrm{~nm}$ in UV light. 
(a)

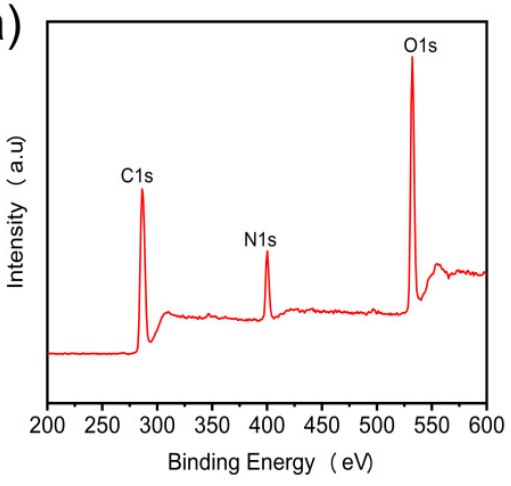

(c)

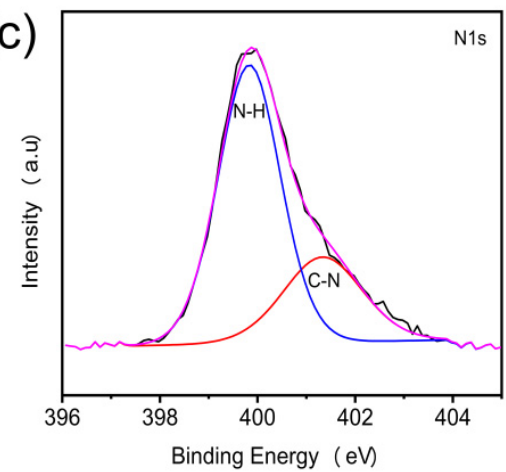

(b)

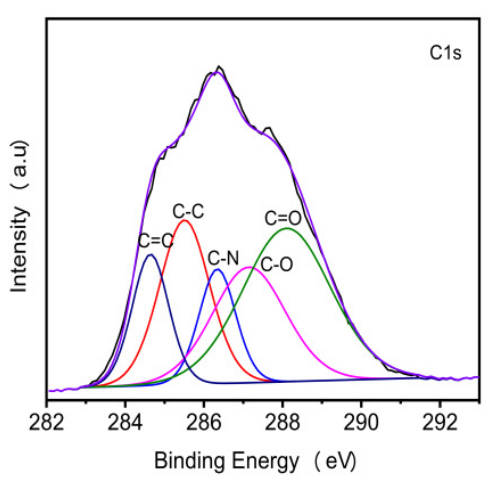

(d)

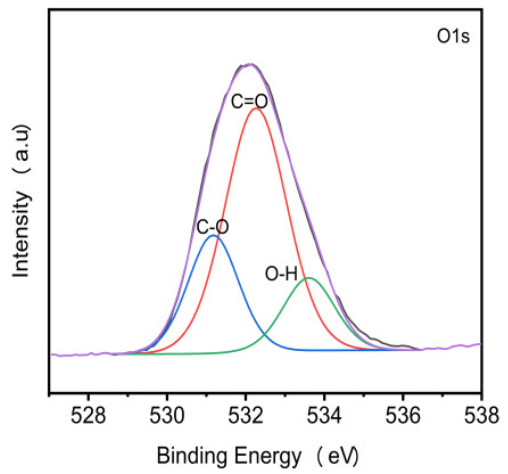

Figure 2. (a) XPS spectrum of N-CQDs, and (b-d) High resolution XPS spectra of C1s, O1s and N1s of N-CQDs, respectively.

(a)

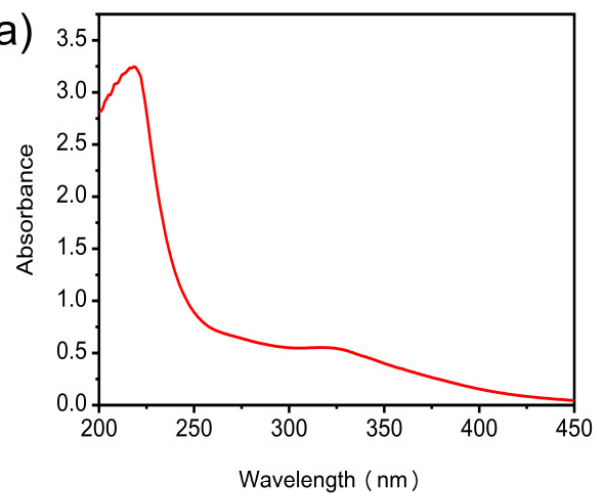

(b)
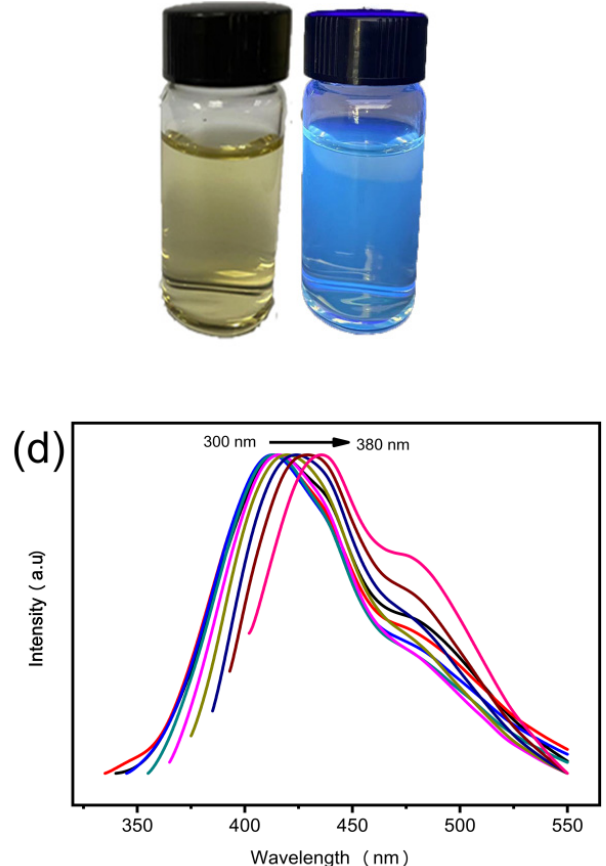

Figure 3. (a) UV-Vis absorption spectrum of N-CQDs, (b) N-CQDs solution under visible light (left) and UV light with the wavelength of $365 \mathrm{~nm}$ (right), respectively, (c) Fluorescence spectra of N-CQDs excited at changed wavelengths, and (d) Normalized fluorescence spectra of N-CQDs excited at wavelength of 300-380 nm. 
Figure $3 c$ displays that the N-CQD samples prepared from L-lactic acid possess very good fluorescence properties. Their fluorescence intensity will be affected by excitation wavelength. Their fluorescence intensity steadily declines as the excitation wavelength increases from $300 \mathrm{~nm}$ to $380 \mathrm{~nm}$ with each increment of $10 \mathrm{~nm}$. The normalized fluorescence spectra of N-CQDs given in Figure $3 \mathrm{~d}$ show that the fluorescence emission peak of N-CQDs would red-shift by $22 \mathrm{~nm}$ from $414 \mathrm{~nm}$ to $436 \mathrm{~nm}$ with the excitation wavelength changing from $300 \mathrm{~nm}$ to $380 \mathrm{~nm}$. This red shift may be caused by the varied sizes of N-CQDs as well as the functional groups on the surface of the N-CQDs [36,50]. Moreover, N-CQDs possess a maximal emission peak at $414 \mathrm{~nm}$ with an excitation wavelength of $310 \mathrm{~nm}$. Meanwhile, the quantum yield of N-CQDs is $46 \%$, which is significantly higher than those of the CQDs synthesized from biomass as carbon source in literatures shown in Table 1.

Table 1. The quantum yield of CQDs synthesized from biomass as a carbon source.

\begin{tabular}{cccc}
\hline Carbon Source & Method & Quantum Yield & Reference \\
\hline Tomato juices & hydrothermal & $3.38 \%$ & {$[40]$} \\
Magnolia flower & hydrothermal & $4.29 \%$ & {$[47]$} \\
Pine wood & hydrothermal & $4.69 \%$ & {$[51]$} \\
Lemon juices & hydrothermal & $5 \%$ & {$[40]$} \\
Adenosine & hydrothermal & $11.3 \%$ & {$[52]$} \\
Prunus avium fruit & hydrothermal & $13 \%$ & {$[53]$} \\
Garlic & hydrothermal & $13 \%$ & {$[54]$} \\
Pigeon feathers & pyrolysis & $24.87 \%$ & {$[55]$} \\
Banana juice & hydrothermal & $32 \%$ & {$[35]$} \\
Ascorbic acid & hydrothermal & $32.07 \%$ & {$[31]$} \\
Black soya beans & pyrolysis & $38.7 \pm 0.64 \%$ & {$[56]$} \\
L-lactic acid & hydrothermal & $46 \%$ & This work \\
\hline
\end{tabular}

\subsection{The Effect of $\mathrm{pH}$ on $\mathrm{N}-\mathrm{CQD}$ s Fluorescence Intensity}

The surface of the obtained N-CQDs includes amino, hydroxyl and carboxyl functional groups, as can be seen by XPS and FTIR. We may utilize these functional groups to detect the effect of $\mathrm{pH}$ values on $\mathrm{N}$-CQDs fluorescence intensity. The fluorescence intensities of $\mathrm{N}$-CQDs with different $\mathrm{pH}$ values at the excitation wavelength of $310 \mathrm{~nm}$ were given in Figure $4 \mathrm{a}, \mathrm{b}$, which clearly show the apparent effects of $\mathrm{pH}$ on N-CQDs fluorescence intensity. As shown in Figure 4c,d, when $\mathrm{pH}$ value increases from 1 to $7, \mathrm{~N}-\mathrm{CQD}$ fluorescence intensity gradually increases and reaches to the maximum as $\mathrm{pH}$ value being 7 . Then the $\mathrm{N}$-CQD fluorescence intensity decreases with rising $\mathrm{pH}$ values from 8 to 14 and reaches a minimum as $\mathrm{pH}$ value being 14 . N-CQDs fluorescence intensity slightly vary as $\mathrm{pH}$ values from 3 to 12 , but they are much lower under strong acid ( $\mathrm{pH}$ being 1 or 2 ) or alkali conditions ( $\mathrm{pH}$ being 13 or 14). In Figure 4c, N-CQDs fluorescence intensity is quenched under acidic conditions while the emission peak of N-CQDs does not change, which may be due to the protonation of amino groups on N-CQDs surface [32]. In Figure 4d, both fluorescence intensity and emission peak of N-CQDs diminish as $\mathrm{pH}$ increases, which may be attribute to the protonation of carboxyl groups on the surface of N-CQDs [43,57].

In short, the $\mathrm{pH}$-dependent fluorescent behavior of N-CQDs might be ascribed to functional groups on the surface of N-CQDs. When the surface functional groups of $\mathrm{N}$ CQDs are protonated, fluorescence quenching occurs mainly due to the agglomeration of $\mathrm{N}$-CQDs particles [58]. Therefore, N-CQDs can be developed for the use in the field of $\mathrm{pH}$ probes based on its sensitivity to $\mathrm{pH}$. 
(a)

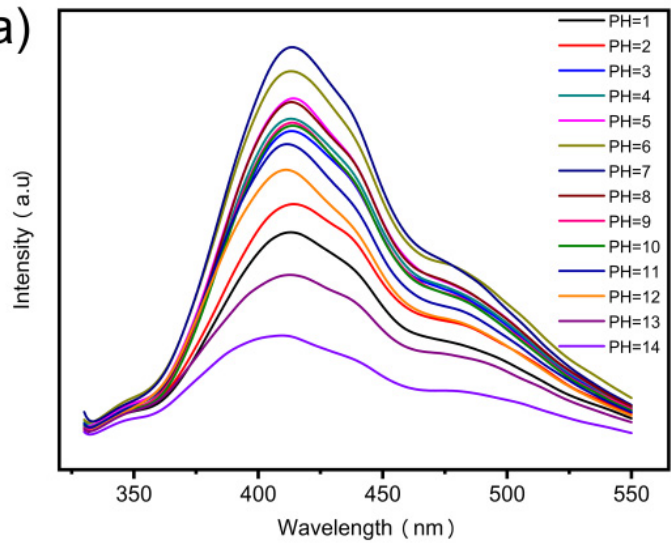

(c)

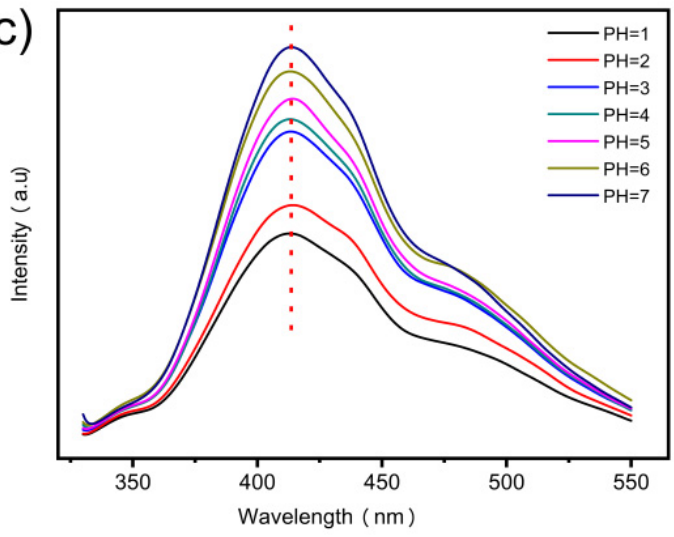

(b)

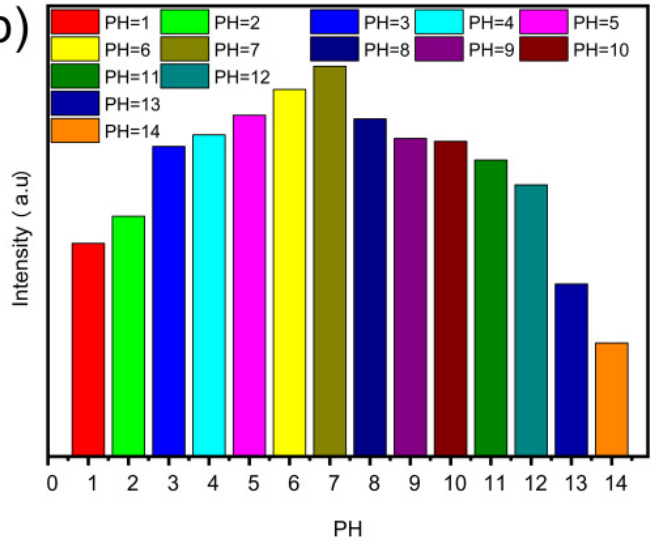

(d)

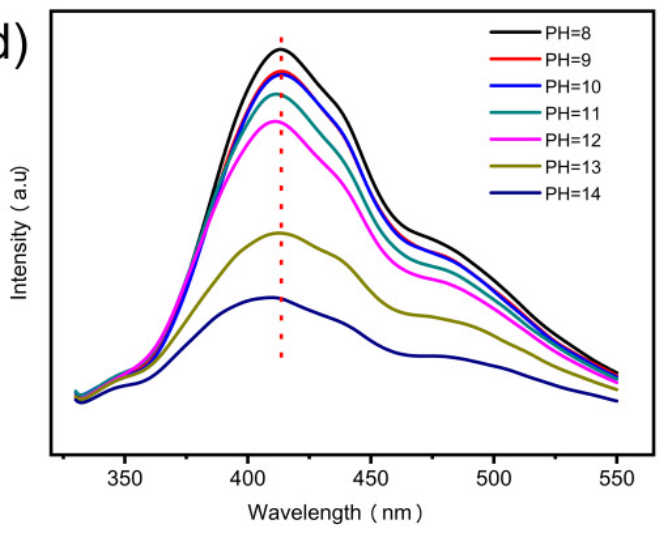

Figure 4. The impact of $\mathrm{pH}$ on N-CQDs fluorescence intensity.(a) The fluorescence spectrum of PH from 1 to 14 N-CQDs, (b) The fluorescence spectrum of PH from 1 to $14 \mathrm{~N}-C Q D s$, (c) The fluorescence spectrum of $\mathrm{PH}$ from 1 to $7 \mathrm{~N}-\mathrm{CQDs}$, (d) The fluorescence spectrum of $\mathrm{PH}$ from 8 to $14 \mathrm{~N}-\mathrm{CQDs}$.

\subsection{Detection and Selection of $\mathrm{Fe}^{3+}$ Ions by N-CQDs}

The hydroxyl, carboxyl and amino surface functional groups of N-CQDs can form complexes with metal ions [59]. As the number of functional groups on the surface of the N-CQDs decreases, its fluorescence intensity would also gradually weaken. Therefore, it may be utilized as a probe to detect metal ions. In this work, to investigate specificity and sensitivity of the obtained N-CQDs to various metal ions, we measured the fluorescence intensities of N-CQDs aqueous solution complexed by different metal ions with the concentration of $1 \mathrm{mM}$ under the same condition. Figure $5 \mathrm{a}, \mathrm{b}$ demonstrated the influence of metal ions on N-CQDs fluorescence intensity at $310 \mathrm{~nm}$ excitation wavelength. Although each metal ion has different effect on N-CQDs fluorescence intensity, this can lessen its fluorescence intensity. The fluorescence quenching performance of $\mathrm{Fe}^{3+}$ ions for $\mathrm{N}-\mathrm{CQDs}$ is obviously superior to that of other metal ions, as N-CQDs fluorescence intensity would decrease by about $99.6 \%$ due to $\mathrm{Fe}^{3+}$ ions, indicating that they have quite an excellent selectivity for $\mathrm{Fe}^{3+}$. To detect the fluorescence quenching of $\mathrm{N}-\mathrm{CQD}$ induced by $\mathrm{Fe}^{3+}$ in combination with other metal ions, a mixture of $\mathrm{Fe}^{3+}$ ions with other metal ions was added to an aqueous solution of N-CQDs, and then the mixed solutions were detected. Figure $5 \mathrm{c}$ exhibited that the effect of $\mathrm{Fe}^{3+}$ ions on $\mathrm{N}-\mathrm{CQD}$ fluorescence quenching is little affected by other metal ions. These findings suggest that they have a specific recognition effect on $\mathrm{Fe}^{3+}$ and a strong anti-interference ability. 

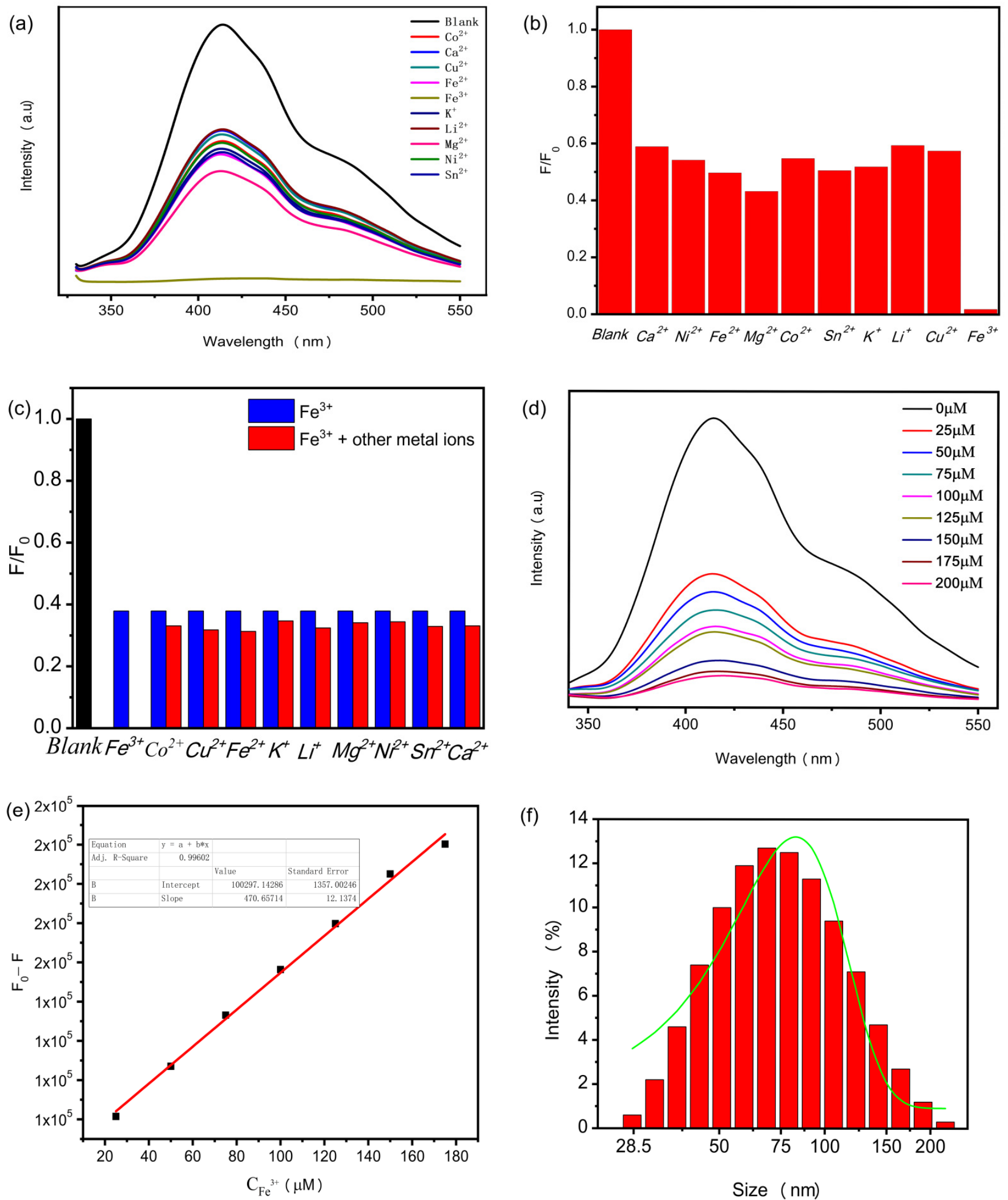

Figure 5. (a,b) Selectivity of N-CQDs for various metal ions, (c) The fluorescence intensities of $\mathrm{N}-\mathrm{CQDs}$ in presence of $\mathrm{Fe}^{3+}$ with various interfering metal ions, (d) Fluorescence spectra of N-CQDs solution with various $\mathrm{Fe}^{3+}$ concentrations, (e) The linearity between the quenching efficiency $\left(F-F_{0}\right)$ and $\mathrm{Fe}^{3+}$ concentrations, (f) Histogram of size distribution of $\mathrm{N}-\mathrm{CQDS}$ in the presence of $\mathrm{Fe}^{3+}$ ions. 
In order to make sure the sensitivity of N-CQDs to $\mathrm{Fe}^{3+}$ ions, the effect of $\mathrm{Fe}^{3+}$ ions concentrations on N-CQDs fluorescence intensity at $310 \mathrm{~nm}$ excitation wavelength was shown in Figure 5d. Its fluorescence intensity steadily declines with $\mathrm{Fe}^{3+}$ concentration increasing from $0 \mu \mathrm{M}$ to $200 \mu \mathrm{M}$. Figure $5 \mathrm{e}$ displays a good linearity between the quenching efficiency (i.e., the difference $\left(F_{0}-F\right)$ ) and $\mathrm{Fe}^{3+}$ concentrations ranging from 25 to $175 \mu \mathrm{M}$ with the correlation coefficient of 0.99602 . Thus, the concentration of $\mathrm{Fe}^{3+}$ ions could be computed using the equation below.

$$
F_{0}-F=470.657 C+100297.143
$$

where $F$ and $F_{0}$ denote the fluorescence intensities of N-CQDs in the presence and the absence of $\mathrm{Fe}^{3+}$, respectively. The concentration of $\mathrm{Fe}^{3+}$ ions is represented by $\mathrm{C}$. According to the above equation, the limit of detection is calculated to be $1.89 \mu \mathrm{M}$ based on three times the standard deviation rule $(3 \delta / \mathrm{k}$, where $\delta$ represents standard deviation of the blank N-CQDs and $\mathrm{k}$ is the slope of the calibration curve, $n=6$ ), and it is far below the requirement that $\mathrm{Fe}^{3+}$ ion concentration in drinking water is less than $5.4 \mu \mathrm{M}$. Table 2 compares the detection capability of the obtained N-CQDs for $\mathrm{Fe}^{3+}$ to that of CQDs for $\mathrm{Fe}^{3+}$ reported in other literatures, in which the linear range of $\mathrm{Fe}^{3+}$ detection was ordered from small to large range. The obtained N-CQDs have quite a broad linear detection range and are far more sensitive to $\mathrm{Fe}^{3+}$ ions.

The complexation of $\mathrm{Fe}^{3+}$ with the carboxyl group, amino group and hydroxyl group on the surface of N-CQDs may be responsible for the fluorescence quenching caused by $\mathrm{Fe}^{3+}[26,60]$. Meanwhile, the $\mathrm{N}$ atom has a large electronegativity, which is conducive to enhancing the electron density distribution on N-CQDs surface and promoting the complexation of $\mathrm{Fe}^{3+}$ with $\mathrm{N}$-CQDs surface functional groups [61]. The complexation will facilitate the rapid movement of electrons between $\mathrm{Fe}^{3+}$ ions and N-CQDs, and lead to the formation of a non-radiative electron/hole recombination [47]. Therefore, $\mathrm{Fe}^{3+}$ ions significantly quench the fluorescence of N-CQDs. Furthermore, the particle size of N-CQDs significantly increases with the addition of $\mathrm{Fe}^{3+}$ ions, for the diameter distributing of NCQDs increases from $2.6 \mathrm{~nm}$ to $62.3 \mathrm{~nm}$ (in Figure 5f), and the green curve in Figure $5 \mathrm{f}$ is obtained by fitting Gaussian function to the particle size of N-CQDs solution after adding $\mathrm{Fe}^{3+}$, which proves that $\mathrm{Fe}^{3+}$ ions complexed with the surface functional groups of N-CQDs. All results show high selectivity and sensitivity of the obtained N-CQDs to $\mathrm{Fe}^{3+}$ ions.

Table 2. Comparison on CQDs for determination of $\mathrm{Fe}^{3+}$ ions.

\begin{tabular}{ccccc}
\hline Materials & Method & Linear Range $(\mu \mathbf{M})$ & $\begin{array}{c}\text { Limit of Detection } \\
(\mu \mathbf{M})\end{array}$ & Reference \\
\hline Sulfanilic acid & solvothermal & $0.025-0.4$ & 2.549 & {$[62]$} \\
Isoleucine and citric acid & hydrothermal & $0-20$ & - & 2.74 \\
Roasted chickpea & Microwave & $11.25-37.5$ & 0.7462 & {$[60]$} \\
Rice residue and lysine & hydrothermal & $3.32-32.26$ & 2.3 & {$[63]$} \\
$\quad$ Citric acid and Tris & hydrothermal & $2-50$ & 3.8 & {$[64]$} \\
L-glutamic acid and & microwave & $8-80$ & 1.95 & {$[65]$} \\
ethylenediamie & hydrothermal & $0-250$ & 1.89 & This work \\
Wheat straw & hydrothermal & $25-175$ & &
\end{tabular}

\section{Conclusions}

In summary, we had been using a one-step hydrothermal technique to create $\mathrm{N}$ CQDs utilizing L-lactic acid as a carbon source and ethylenediamine as a nitrogen source, respectively. The N-CQDs created are nanospheres with outstanding fluorescence and good solubility in water, while the quantum yields of N-CQDs (being $46 \%$ ) are significantly higher than that of the CQDs reported in literatures. Furthermore, the emission intensity of $\mathrm{N}-\mathrm{CQD}$ s exhibits excitation wavelength dependence. Their fluorescence intensity steadily 
decreases as the excitation wavelength increases from 310 to $380 \mathrm{~nm}$. Meanwhile, the fluorescence intensity of N-CQDs shows sensitivity to $\mathrm{pH}$ values. In comparison to other metal ions, N-CQDs have quite a high specificity and sensitivity for $\mathrm{Fe}^{3+}$ ions in a wide range of concentrations with the low detection limit of $1.89 \mu \mathrm{M}$. Therefore, the N-CQDs created might be employed as fluorescent probe for $\mathrm{pH}$ and $\mathrm{Fe}^{3+}$ ions.

Author Contributions: Conceptualization, Q.G. and K.C.; methodology, L.Q.; software, W.G.; validation, Q.G., K.C. and Q.Z.; formal analysis, K.C.; investigation, M.G.; resources, Q.G.; data curation, W.G.; writing — original draft preparation, K.C.; writing—review and editing, Q.G.; visualization, K.C.; supervision, Q.G.; project administration, Q.G.; funding acquisition, Q.G. All authors have read and agreed to the published version of the manuscript.

Funding: This work was supported by National Natural Science Foundation of China (50573032, 31200451), Priority Academic Program Development of Jiangsu Higher Education Institutions (PAPD).

Institutional Review Board Statement: Not applicable.

Informed Consent Statement: Not applicable.

Data Availability Statement: The data presented in this study are available on request from the corresponding author.

Acknowledgments: The authors gratefully acknowledge the facilities support from Advanced Analysis and Testing Center of Nanjing Forestry University and Jiangsu Key Lab for the Chemistry \&Utilization of Agricultural and Forest Biomass.

Conflicts of Interest: The authors declare no conflict of interest.

\section{References}

1. Choi, Y.; Thongsai, N.; Chae, A.; Jo, S.; Kang, E.B.; Paoprasert, P.; Park, S.Y.; In, I. Microwave-assisted synthesis of luminescent and biocompatible lysine-based carbon quantum dots. J. Ind. Eng. Chem. 2017, 47, 329-335. [CrossRef]

2. Wu, M.; Wang, Y.; Wu, W.; Hu, C.; Wang, X.; Zheng, J.; Li, Z.; Jiang, B.; Qiu, J. Preparation of functionalized water-soluble photoluminescent carbon quantum dots from petroleum coke. Carbon 2014, 78, 480-489. [CrossRef]

3. Architha, N.; Ragupathi, M.; Shobana, C.; Selvankumar, T.; Kumar, P.; Lee, Y.S.; Kalai Selvan, R. Microwave-assisted green synthesis of fluorescent carbon quantum dots from Mexican Mint extract for $\mathrm{Fe}^{3+}$ detection and bio-imaging applications. Environ. Res. 2021, 199, 111263. [CrossRef]

4. Yadegari, A.; Khezri, J.; Esfandiari, S.; Mahdavi, H.; Karkhane, A.A.; Rahighi, R.; Heidarimoghadam, R.; Tayebi, L.; Hashemi, E.; Farmany, A. Bottom-up synthesis of nitrogen and oxygen co-decorated carbon quantum dots with enhanced DNA plasmid expression. Colloids Surf. B Biointerfaces 2019, 184, 110543. [CrossRef]

5. Liu, Q.; Guo, B.; Rao, Z.; Zhang, B.; Gong, J.R. Strong two-photon-induced fluorescence from photostable, biocompatible nitrogendoped graphene quantum dots for cellular and deep-tissue imaging. Nano Lett. 2013, 13, 2436-2441. [CrossRef] [PubMed]

6. Hua, X.W.; Bao, Y.W.; Wu, F.G. Fluorescent Carbon Quantum Dots with Intrinsic Nucleolus-Targeting Capability for Nucleolus Imaging and Enhanced Cytosolic and Nuclear Drug Delivery. ACS Appl. Mater. Interfaces 2018, 10, 10664-10677. [CrossRef]

7. Khodadadei, F.; Safarian, S.; Ghanbari, N. Methotrexate-loaded nitrogen-doped graphene quantum dots nanocarriers as an efficient anticancer drug delivery system. Mater. Sci. Eng. C Mater. Biol. Appl. 2017, 79, 280-285. [CrossRef] [PubMed]

8. Zhuo, Y.; Miao, H.; Zhong, D.; Zhu, S.; Yang, X. One-step synthesis of high quantum-yield and excitation-independent emission carbon dots for cell imaging. Mater. Lett. 2015, 139, 197-200. [CrossRef]

9. Niu, W.-J.; Li, Y.; Zhu, R.-H.; Shan, D.; Fan, Y.-R.; Zhang, X.-J. Ethylenediamine-assisted hydrothermal synthesis of nitrogen-doped carbon quantum dots as fluorescent probes for sensitive biosensing and bioimaging. Sens. Actuators B Chem. 2015, 218, 229-236. [CrossRef]

10. Murugan, N.; Prakash, M.; Jayakumar, M.; Sundaramurthy, A.; Sundramoorthy, A.K. Green synthesis of fluorescent carbon quantum dots from Eleusine coracana and their application as a fluorescence 'turn-off' sensor probe for selective detection of $\mathrm{Cu}^{2+}$. Appl. Surf. Sci. 2019, 476, 468-480. [CrossRef]

11. Kalaiyarasan, G.; Joseph, J. Cholesterol derived carbon quantum dots as fluorescence probe for the specific detection of hemoglobin in diluted human blood samples. Mater. Sci. C 2019, 94, 580-586. [CrossRef]

12. Paulo, S.; Stoica, G.; Cambarau, W.; Martinez-Ferrero, E.; Palomares, E. Carbon quantum dots as new hole transport material for perovskite solar cells. Synthetic 2016, 222, 17-22. [CrossRef]

13. Chava, R.K.; Im, Y.; Kang, M. Nitrogen doped carbon quantum dots as a green luminescent sensitizer to functionalize ZnO nanoparticles for enhanced photovoltaic conversion devices. Mater. Res. Bull. 2017, 94, 399-407. [CrossRef]

14. Xu, X.; Ray, R.; Gu, Y.; Ploehn, H.J.; Gearheart, L.; Raker, K.; Scrivens, W.A. Electrophoretic analysis and purification of fluorescent single-walled carbon nanotube fragments. J. Am. Chem. Soc. 2004, 126, 12736-12737. [CrossRef] 
15. Liang, Z.; Kang, M.; Payne, G.F.; Wang, X.; Sun, R. Probing Energy and Electron Transfer Mechanisms in Fluorescence Quenching of Biomass Carbon Quantum Dots. ACS Appl. Mater. Interfaces 2016, 8, 17478-17488. [CrossRef] [PubMed]

16. Gonçalves, H.; Jorge, P.A.S.; Fernandes, J.R.A.; Esteves da Silva, J.C.G. $\mathrm{Hg}$ (II) sensing based on functionalized carbon dots obtained by direct laser ablation. Sens. Actuators B Chem. 2010, 145, 702-707. [CrossRef]

17. Dong, Y.; Zhou, N.; Lin, X.; Lin, J.; Chi, Y.; Chen, G. Extraction of Electrochemiluminescent Oxidized Carbon Quantum Dots from Activated Carbon. Chem. Mater. 2010, 22, 5895-5899. [CrossRef]

18. Xiao, D.; Yuan, D.; He, H.; Gao, M. Microwave assisted one-step green synthesis of fluorescent carbon nanoparticles from ionic liquids and their application as novel fluorescence probe for quercetin determination. J. Lumin. 2013, 140, 120-125. [CrossRef]

19. Shen, T.; Wang, Q.; Guo, Z.; Kuang, J.; Cao, W. Hydrothermal synthesis of carbon quantum dots using different precursors and their combination with TiO2 for enhanced photocatalytic activity. Ceram. Int. 2018, 44, 11828-11834. [CrossRef]

20. Zhu, S.; Song, Y.; Wang, J.; Wan, H.; Zhang, Y.; Ning, Y.; Yang, B. Photoluminescence mechanism in graphene quantum dots: Quantum confinement effect and surface/edge state. Nano Today 2017, 13, 10-14. [CrossRef]

21. Lin, L.; Song, X.; Chen, Y.; Rong, M.; Zhao, T.; Wang, Y.; Jiang, Y.; Chen, X. Intrinsic peroxidase-like catalytic activity of nitrogendoped graphene quantum dots and their application in the colorimetric detection of $\mathrm{H} 2 \mathrm{O} 2$ and glucose. Anal. Chim. Acta 2015, 869, 89-95. [CrossRef] [PubMed]

22. Guo, Y.; Cao, F.; Li, Y. Solid phase synthesis of nitrogen and phosphor co-doped carbon quantum dots for sensing Fe ${ }^{3+}$ and the enhanced photocatalytic degradation of dyes. Sens. Actuators B Chem. 2018, 255, 1105-1111. [CrossRef]

23. Pu, Z.-F.; Wen, Q.-L.; Yang, Y.-J.; Cui, X.-M.; Ling, J.; Liu, P.; Cao, Q.-E. Fluorescent carbon quantum dots synthesized using phenylalanine and citric acid for selective detection of $\mathrm{Fe}^{3+}$ ions. Spectrochim. Acta Part A Mol. Biomol. Spectrosc. 2020, 229,117944 [CrossRef]

24. Zhou, J.; Sheng, Z.; Han, H.; Zou, M.; Li, C. Facile synthesis of fluorescent carbon dots using watermelon peel as a carbon source. Mater. Lett. 2012, 66, 222-224. [CrossRef]

25. Mehta, V.N.; Jha, S.; Kailasa, S.K. One-pot green synthesis of carbon dots by using Saccharum officinarum juice for fluorescent imaging of bacteria (Escherichia coli) and yeast (Saccharomyces cerevisiae) cells. Mater. Sci. Eng. C Mater. Biol. Appl. 2014, 38, 20-27. [CrossRef] [PubMed]

26. Yang, L.; Sun, X.; Li, D.; Qu, C.; Liu, H.; Wei, M.; Liu, X.; Yang, J. Facile Synthesis of Fluorescent Nitrogen-Doped Carbon Quantum Dots Using Scindapsus as a Carbon Source. Phys. Status Solidi 2019, 216, 1800404. [CrossRef]

27. Lin, L.; Luo, Y.; Tsai, P.; Wang, J.; Chen, X. Metal ions doped carbon quantum dots: Synthesis, physicochemical properties, and their applications. TrAC Trends Anal. Chem. 2018, 103, 87-101. [CrossRef]

28. Sun, Y.; Shen, C.; Wang, J.; Lu, Y. Facile synthesis of biocompatible N, S-doped carbon dots for cell imaging and ion detecting. RSC Adv. 2015, 5, 16368-16375. [CrossRef]

29. Lu, W.; Gong, X.; Nan, M.; Liu, Y.; Shuang, S.; Dong, C. Comparative study for N and S doped carbon dots: Synthesis, characterization and applications for $\mathrm{Fe}^{3+}{ }^{3+}$ ) probe and cellular imaging. Anal. Chim. Acta 2015, 898, 116-127. [CrossRef] [PubMed]

30. Qi, H.; Teng, M.; Liu, M.; Liu, S.; Li, J.; Yu, H.; Teng, C.; Huang, Z.; Liu, H.; Shao, Q.; et al. Biomass-derived nitrogen-doped carbon quantum dots: Highly selective fluorescent probe for detecting $\mathrm{Fe}^{3+}$ ions and tetracyclines. J. Colloid Interface Sci. 2019, 539, 332-341. [CrossRef] [PubMed]

31. Du, F.; Cheng, Z.; Tan, W.; Sun, L.; Ruan, G. Development of sulfur doped carbon quantum dots for highly selective and sensitive fluorescent detection of $\mathrm{Fe}^{2+}$ and $\mathrm{Fe}^{3+}$ ions in oral ferrous gluconate samples. Spectrochim. Acta Part A Mol. Biomol. Spectrosc. 2020, 226, 117602. [CrossRef] [PubMed]

32. Chen, X.; Bai, J.; Ma, Y.; Yuan, G.; Mei, J.; Zhang, L.; Ren, L. Multifunctional sensing applications of biocompatible N-doped carbon dots as $\mathrm{pH}$ and $\mathrm{Fe}^{3+}$ sensors. Microchem. J. 2019, 149, 103981. [CrossRef]

33. Chen, Y.; Sun, X.; Pan, W.; Yu, G.; Wang, J. Fe ${ }^{3+}$-Sensitive Carbon Dots for Detection of $\mathrm{Fe}^{3+}$ in Aqueous Solution and Intracellular Imaging of $\mathrm{Fe}^{3+}$ Inside Fungal Cells. Front. Chem. 2020, 7, 911. [CrossRef]

34. Xu, L.; Zhang, Y.; Pan, H.; Xu, N.; Mei, C.; Mao, H.; Zhang, W.; Cai, J.; Xu, C. Preparation and Performance of Radiata-Pine-Derived Polyvinyl Alcohol/Carbon Quantum Dots Fluorescent Films. Materials 2020, 13, 67. [CrossRef]

35. Chaudhary, N.; Gupta, P.K.; Eremin, S.; Solanki, P.R. One-step green approach to synthesize highly fluorescent carbon quantum dots from banana juice for selective detection of copper ions. J. Environ. Chem. Eng. 2020, 8, 103720. [CrossRef]

36. Cui, X.; Wang, Y.; Liu, J.; Yang, Q.; Zhang, B.; Gao, Y.; Wang, Y.; Lu, G. Dual functional N- and S-co-doped carbon dots as the sensor for temperature and $\mathrm{Fe}^{3+}$ ions. Sens. Actuators B Chem. 2017, 242, 1272-1280. [CrossRef]

37. Yang, Z.; Xu, M.; Liu, Y.; He, F.; Gao, F.; Su, Y.; Wei, H.; Zhang, Y. Nitrogen-doped, carbon-rich, highly photoluminescent carbon dots from ammonium citrate. Nanoscale 2014, 6, 1890-1895. [CrossRef] [PubMed]

38. Guo, Y.; Zhao, W. Hydrothermal synthesis of highly fluorescent nitrogen-doped carbon quantum dots with good biocompatibility and the application for sensing ellagic acid. Spectrochim. Acta Part A Mol. Biomol. Spectrosc. 2020, 240, 118580. [CrossRef] [PubMed]

39. Qu, C.; Zhang, D.; Yang, R.; Hu, J.; Qu, L. Nitrogen and sulfur co-doped graphene quantum dots for the highly sensitive and selective detection of mercury ion in living cells. Spectrochim. Acta Part A Mol. Biomol. Spectrosc. 2019, 206, 588-596. [CrossRef] [PubMed]

40. Hashemi, F.; Heidari, F.; Mohajeri, N.; Mahmoodzadeh, F.; Zarghami, N. Fluorescence Intensity Enhancement of Green Carbon Dots: Synthesis, Characterization and Cell Imaging. Photochem. Photobiol. 2020, 96, 1032-1040. [CrossRef] 
41. Deka, M.J.; Dutta, A.; Chowdhury, D. Tuning the wettability and photoluminescence of graphene quantum dots via covalent modification. New J. Chem. 2018, 42, 355-362. [CrossRef]

42. Ahmadian-Fard-Fini, S.; Ghanbari, D.; Amiri, O.; Salavati-Niasari, M. Electro-spinning of cellulose acetate nanofibers/Fe/carbon dot as photoluminescence sensor for mercury (II) and lead (II) ions. Carbohydr. Polym. 2020, 229, 115428. [CrossRef] [PubMed]

43. Jin, S.H.; Kim, D.H.; Jun, G.H.; Hong, S.H.; Jeon, S. Tuning the photoluminescence of graphene quantum dots through the charge transfer effect of functional groups. ACS Nano 2013, 7, 1239-1245. [CrossRef]

44. Zou, W.; Ma, X.; Zheng, P. Preparation and functional study of cellulose/carbon quantum dot composites. Cellulose 2020, 27, 2099-2113. [CrossRef]

45. Hallaj, T.; Amjadi, M.; Mirbirang, F. S, N-doped carbon quantum dots enhanced Luminol-Mn(IV) chemiluminescence reaction for detection of uric acid in biological fluids. Microchem. J. 2020, 156, 104841. [CrossRef]

46. Wei, W.; Xu, C.; Wu, L.; Wang, J.; Ren, J.; Qu, X. Non-Enzymatic-Browning-Reaction: A Versatile Route for Production of Nitrogen-Doped Carbon Dots with Tunable Multicolor Luminescent Display. Sci. Rep. 2014, 4, 3564. [CrossRef] [PubMed]

47. Wang, C.; Shi, H.; Yang, M.; Yan, Y.; Liu, E.; Ji, Z.; Fan, J. Facile synthesis of novel carbon quantum dots from biomass waste for highly sensitive detection of iron ions. Mater. Res. Bull. 2020, 124, 110730. [CrossRef]

48. Zhang, R.; Chen, W. Nitrogen-doped carbon quantum dots: Facile synthesis and application as a "turn-off" fluorescent probe for detection of $\mathrm{Hg}^{2+}$ ions. Biosens. Bioelectron. 2014, 55, 83-90. [CrossRef]

49. Jiang, K.; Feng, X.; Gao, X.; Wang, Y.; Cai, C.; Li, Z.; Lin, H. Preparation of Multicolor Photoluminescent Carbon Dots by Tuning Surface States. Nanomaterials 2019, 9, 529. [CrossRef]

50. Zhou, J.; Yang, Y.; Zhang, C.-Y. A low-temperature solid-phase method to synthesize highly fluorescent carbon nitride dots with tunable emission. Chem. Commun. 2013, 49, 8605-8607. [CrossRef]

51. Zhao, S.; Song, X.; Chai, X.; Zhao, P.; He, H.; Liu, Z. Green production of fluorescent carbon quantum dots based on pine wood and its application in the detection of $\mathrm{Fe}^{3+}$. J. Clean. Prod. 2020, 263, 121561. [CrossRef]

52. Zhang, W.J.; Liu, S.G.; Han, L.; Luo, H.Q.; Li, N.B. A ratiometric fluorescent and colorimetric dual-signal sensing platform based on N-doped carbon dots for selective and sensitive detection of copper(II) and pyrophosphate ion. Sens. Actuators B Chem. 2019, 283, 215-221. [CrossRef]

53. Edison, T.N.J.I.; Atchudan, R.; Shim, J.-J.; Kalimuthu, S.; Ahn, B.-C.; Lee, Y.R. Turn-off fluorescence sensor for the detection of ferric ion in water using green synthesized $\mathrm{N}$-doped carbon dots and its bio-imaging. J. Photochem. Photobiol. B Biol. 2016, 158, 235-242. [CrossRef] [PubMed]

54. Chen, Y.; Wu, Y.; Weng, B.; Wang, B.; Li, C. Facile synthesis of nitrogen and sulfur co-doped carbon dots and application for Fe(III) ions detection and cell imaging. Sens. Actuators B Chem. 2016, 223, 689-696. [CrossRef]

55. Ye, Q.; Yan, F.; Luo, Y.; Wang, Y.; Zhou, X.; Chen, L. Formation of N, S-codoped fluorescent carbon dots from biomass and their application for the selective detection of mercury and iron ion. Spectrochim. Acta Part A Mol. Biomol. Spectrosc. 2017, 173, 854-862. [CrossRef]

56. Jia, J.; Lin, B.; Gao, Y.; Jiao, Y.; Li, L.; Dong, C.; Shuang, S. Highly luminescent N-doped carbon dots from black soya beans for free radical scavenging, $\mathrm{Fe}^{3+}$ sensing and cellular imaging. Spectrochim. Acta Part A Mol. Biomol. Spectrosc. 2019, 211, 363-372. [CrossRef]

57. Pan, D.; Zhang, J.; Li, Z.; Wu, C.; Yan, X.; Wu, M. Observation of pH-, solvent-, spin-, and excitation-dependent blue photoluminescence from carbon nanoparticles. Chem. Commun. 2010, 46, 3681-3683. [CrossRef]

58. Zhang, B.; Liu, Y.; Ren, M.; Li, W.; Zhang, X.; Vajtai, R.; Ajayan, P.M.; Tour, J.M.; Wang, L. Sustainable Synthesis of Bright Green Fluorescent Nitrogen-Doped Carbon Quantum Dots from Alkali Lignin. ChemSusChem 2019, 12, 4202-4210. [CrossRef] [PubMed]

59. Liu, R.; Li, H.; Kong, W.; Liu, J.; Liu, Y.; Tong, C.; Zhang, X.; Kang, Z. Ultra-sensitive and selective $\mathrm{Hg}^{2+}$ detection based on fluorescent carbon dots. Mater. Res. Bull. 2013, 48, 2529-2534. [CrossRef]

60. Jiang, Y.; Han, Q.; Jin, C.; Zhang, J.; Wang, B. A fluorescence turn-off chemosensor based on N-doped carbon quantum dots for detection of $\mathrm{Fe}^{3+}$ in aqueous solution. Mater. Lett. 2015, 141, 366-368. [CrossRef]

61. Wu, H.; Jiang, J.; Gu, X.; Tong, C. Nitrogen and sulfur co-doped carbon quantum dots for highly selective and sensitive fluorescent detection of Fe(III) ions and L-cysteine. Microchim. Acta 2017, 184, 2291-2298. [CrossRef]

62. Deng, Y.; Qian, J.; Zhou, Y.; Lu, F. Regulatory Preparation of N/S Doped Carbon Quantum Dots and Their Applications as Fe(III) Ion Sensors. ChemistrySelect 2020, 5, 5306-5311. [CrossRef]

63. Başoğlu, A.; Ocak, Ü.; Gümrükçüoğlu, A. Synthesis of Microwave-Assisted Fluorescence Carbon Quantum Dots Using RoastedChickpeas and its Applications for Sensitive and Selective Detection of $\mathrm{Fe}^{\left({ }^{+}\right.}$) Ions. J. Fluoresc. 2020, 30, 515-526. [CrossRef] [PubMed]

64. Yang, X.; Zhuo, Y.; Zhu, S.; Luo, Y.; Feng, Y.; Dou, Y. Novel and green synthesis of high-fluorescent carbon dots originated from honey for sensing and imaging. Biosens. Bioelectron. 2014, 60, 292-298. [CrossRef] [PubMed]

65. Zhou, M.; Zhou, Z.; Gong, A.; Zhang, Y.; Li, Q. Synthesis of highly photoluminescent carbon dots via citric acid and Tris for iron(III) ions sensors and bioimaging. Talanta 2015, 143, 107-113. [CrossRef] [PubMed]

66. Yuan, M.; Zhong, R.; Gao, H.; Li, W.; Yun, X.; Liu, J.; Zhao, X.; Zhao, G.; Zhang, F. One-step, green, and economic synthesis of water-soluble photoluminescent carbon dots by hydrothermal treatment of wheat straw, and their bio-applications in labeling, imaging, and sensing. Appl. Surf. Sci. 2015, 355, 1136-1144. [CrossRef] 